ITEJ Juli-2020, Volume 5 Nomor 2 Page 80 - 87

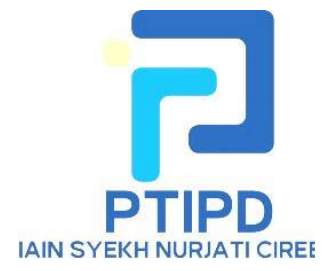

ITEJ

Information Technology Engineering Journals eISSN : $\underline{2548-2157}$

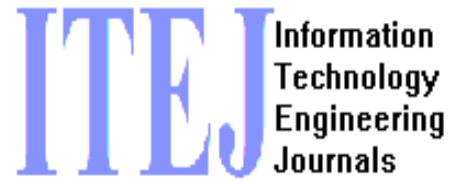

Url : https://syekhnurjati.ac.id/journal/index.php/itej

Email : itej@syekhnurjati.ac.id

\title{
Designing a Lecture Room Monitor System with an Android Application Based on the Chip's ESP8266
}

\author{
Ari Yuliati ${ }^{1}$ \\ Teknik Elektro \\ Univ. Muhammadiyah \\ Tasikmalaya \\ ${ }^{1}$ aryuli@umtas.ac.id
}

\author{
Fajar Hafid Abdilah \\ Teknik Elektro \\ Univ. Muhammadiyah \\ Tasikmalaya
}

\author{
Eddy Samsoleh \\ Teknik Elektro \\ Univ. Muhammadiyah \\ Tasikmalaya
}

\begin{abstract}
The classroom monitoring system with an android application based on the ESP8266 chip was created to solve problems on campus in finding unused rooms and to provide solutions to the problems of finding classroom thus far by using inefficient manual methods. The monitor system was made to determine the status of classroom usage with a passive infrared (PIR) sensor which functions to detect human presence in the room and a light sensor with a Light Depent Resistor $(L D R)$ to detect the use of projector in the room. The two sensors are connected to the ESP8266 chip which is connected to a realtime database via the internet. The android application is specifically made to access monitoring data stored in a realtime database throughout it is connected to the internet. The results of this system test the PIR sensor reaches a maximum distance of 4 meters, a time delay of about 3 minutes, a reliable tool, and low cost.
\end{abstract}

Keywords - ESP8266, sensor, android, realtime database

\section{Pendahuluan}

Ketika proses perkuliahan hendak dilaksanakan, seringkali mahasiswa atau dosen mengalami kesulitan mencari ruangan untuk aktivitas perkuliahan maupun aktivitas di luar mata kuliah seperti kuliah tambahan, seminar, dan kegiatan lain yang dilakukan diluar jam kuliah. Sistem yang berjalan masih kurang memuaskan dikarenakan proses pencarian ruangan masih menggunakan tindakan manual seperti bertanya kepada bagian tata usaha atau kepada dosen yang mengajar di dalam ruangan tersebut, sehingga masih banyak mahasiswa yang harus bertanya ke banyak tempat untuk mendapatkan informasi kelas yang tidak dipakai. Riset terkait yang dilakukan oleh Albert Gifson dan Slamet[7] bahwa sistem pemantauan ruangan jarak jauh dapat dibuat dengan menggunakan sensor PIR untuk mendeteksi keberadaan manusia yang terhubung dengan mikrokontroler AT89S52. Mikrokontroler AT89S52 yang digunakan tidak dilengkapi dengan wifi untuk mengirim data jarak jauh dan harus menggunakan ponsel yang terhubung dengan mikrokontroler AT89S52 dengan RS232 untuk mengirim data dari sensor dengan sms dari gawai tersebut. Perkembangan teknologi pengiriman data jarak jauh tidak menggunakan sms dari gawai yang terhubung dengan mikrokontroler, dengan kehadiran sebuah modul 
wifi yang memiliki fungsi yang sama dengan mikrokontroler AT89S52, yaitu chip ESP8266. Penelitian ini mencoba mengembangkan sistem yang ada untuk pendekatan solusi masalah pencarian ruangan yang terjadi di kampus dengan menganalisis dan merancang monitoring ruangan untuk mengetahui ruangan yang sedang dipakai, ruangan tidak sedang dipakai, dan memonitor penggunaan proyektor dalam ruangan tersebut.

\section{LANDASAN TEORI}

Penelitian dimulai dengan literasi dari beberapa penelitian sebelumnya serta berhubungan, yaitu peneliti Agung Prijambodo[2], Fauzan Jaya, dkk.[6], Gifson dan Slamet[7].

\section{A. WeMos D1 Mini}

WeMos D1 Mini merupakan module development board yang berbasis wifi dari keluarga ESP8266, serta NodeMCU dapat diprogram menggunakan software IDE arduino. Salah satu kelebihan dari WeMos D1 mini ini dibandingkan dengan module development board berbasis ESP8266 lainnya yaitu adanya module shield untuk pendukung hardware plug and play.

\section{B. Sensor PIR}

Sensor PIR adalah perangkat yang terbuat dari bahan kristal yang dapat menghasilkan muatan listrik ketika terkena radiasi inframerah, ketika besar radiasi yang mengenai kristal berubah, jumlah muatan listrik dari kristal juga berubah dan dapat diukur dengan perangkat sensitifitas yang ada dalam sensor yang terdiri dari amplifier dan komparator.

Sensor PIR dilengkapi dengan lensa fresnel FL65 terbuat dari bahan transmisi inframerah yang memiliki jangkauan transmisi IR 8 hingga $14 \mu \mathrm{m}$ yang paling sensitif terhadap radiasi tubuh manusia. Sensor dirancang agar alurnya menghadap elemen penginderaan IR sehingga permukaan yang halus disajikan ke sisi subjek lensa dengan bagian luar selungkup yang menampung sensor.

\section{Light Depent Sensor (LDR)}

LDR atau fotoresistor adalah komponen elektronik yang resistansinya akan menurun jika ada penambahan intensitas cahaya yang mengenainya. Fotoresistor dibuat dari semikonduktor beresistansi tinggi yang tidak dilindungi dari cahaya. Jika cahaya yang mengenainya memiliki frekuensi yang cukup tinggi, foton yang diserap oleh semikonduktor akan menyebabkan elektron memiliki energi yang cukup untuk meloncat ke pita konduksi. Elektron bebas yang dihasilkan (dan pasangan lubangnya) akan mengalirkan listrik, sehingga menurunkan resistansinya.

\section{Realtime Database}

Realtime database adalah sistem basis data yang menggunakan pemrosesan waktu nyata untuk menangani beban kerja yang kondisinya terus berubah. Ini berbeda dari database tradisional yang berisi data persisten, sebagian besar tidak terpengaruh oleh waktu.

\section{E. Android Studio}

Android studio adalah Lingkungan Pengembangan Terpadu (Integrated Development Environment / IDE) resmi untuk pengembangan aplikasi android, yang didasarkan pada IntelliJ IDEA. Selain sebagai editor kode dan fitur developer IntelliJ yang andal, android studio menawarkan banyak fitur yang meningkatkan produktivitas dalam membuat aplikasi Android.

\section{METODE PENELITIAN}


Metodologi penelitian yang dilakukan dalam penelitian ini adalah studi literatur, analisa kebutuhan, perancangan, evaluasi design, implementasi, dan pengujian. Berikut adalah gambar blok diagram sistem seperti pada Gambar 1 dan skema rancangan sistem monitor ruang kuliah pada Gambar 2.

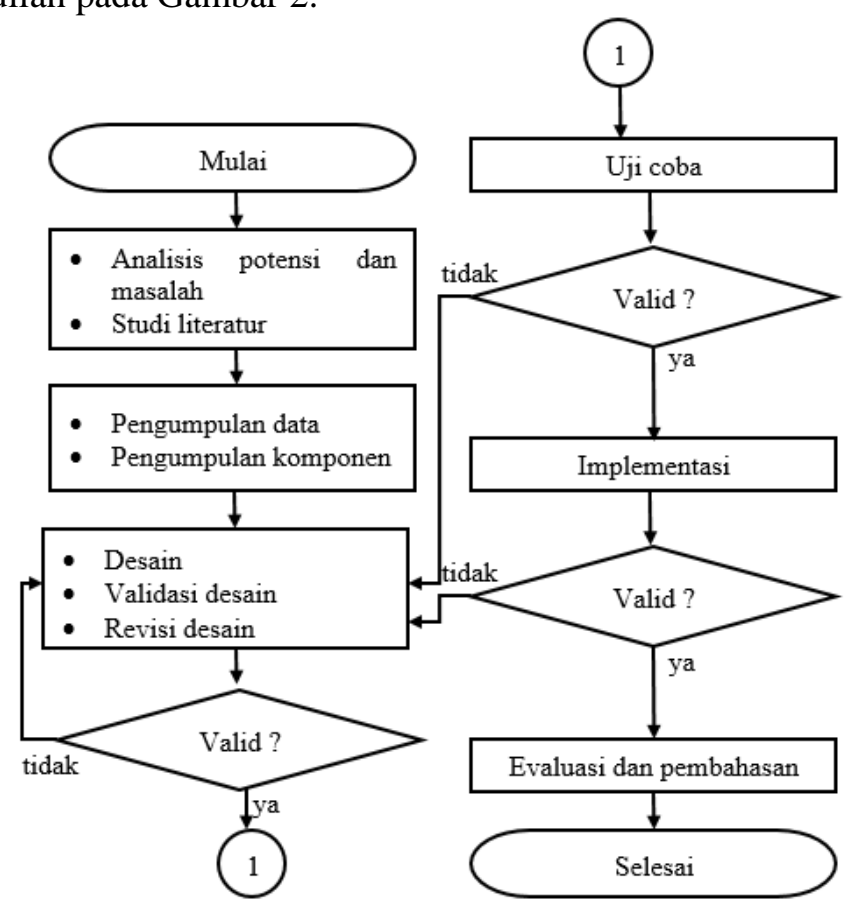

Gambar 1. Alur penelitian

Untuk produk yang akan dirancang dapat dilihat dalam skema Gambar 2 berikut.

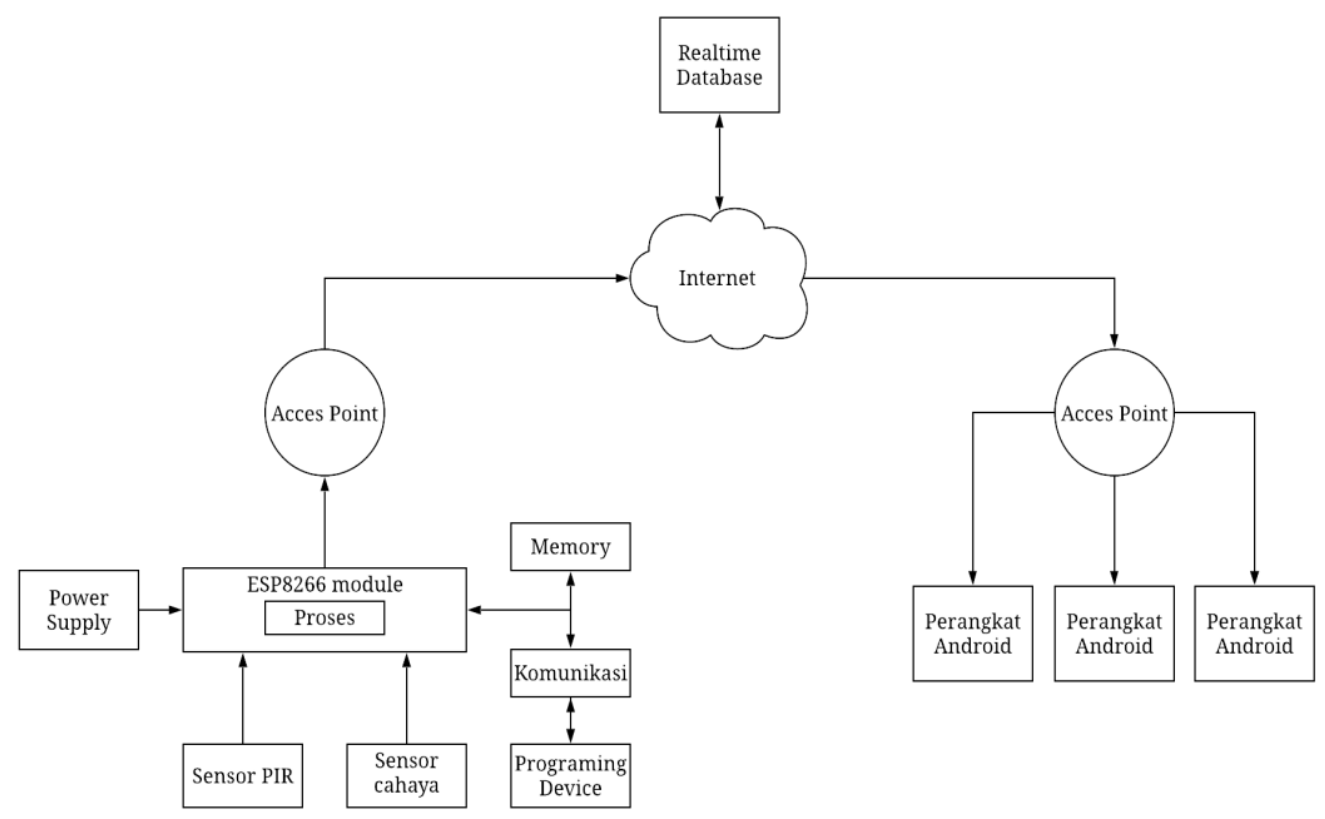

Gambar 2. Skema rancangan sistem monitor ruang kuliah 
Instrumen pengujian reliabilitas instrumen ditekankan dengan menggunakan rumus kuder richardson (kr.21)[13] yaitu sebagai berikut:

$$
r_{i}=\frac{k}{(k-1)} \cdot\left(1-\frac{M \cdot(k-M)}{k \cdot S_{t}^{2}}\right)
$$

Keterangan:

$$
\begin{array}{ll}
\mathrm{r}_{\mathrm{i}} & =\text { reliabilitas instrumen } \\
\mathrm{k} & =\text { jumlah item dalam instrumen } \\
\mathrm{M} & =\text { mean skor total antara subyek } \\
\mathrm{S}_{\mathrm{t}}{ }^{2} & =\text { varians total }
\end{array}
$$

Rumus untuk varians total adalah berlaku:

$$
s_{t}{ }^{2}=\frac{\sum x^{2}-\left(\frac{\left(\sum x\right)^{2}}{n}\right)}{n}
$$

Keterangan:

$$
\begin{array}{ll}
\mathrm{S}_{\mathrm{t}}{ }^{2} & =\text { varians total } \\
n & =\text { banyaknya subjek } \\
\Sigma \mathrm{x}^{2} & =\text { jumlah kuadrat item } \\
(\Sigma \mathrm{x})^{2} & =\text { kuadrat jumlah item }
\end{array}
$$

Setelah koefisien reliabilitas diketahui, kemudian hasilnya dapat diinterpretasikan sebagai standar[14] digunakan sebagai kategori untuk memutuskan instrumen realiabel atau tidak:

\section{HASIL DAN PEMBAHASAN}

Hasil dari perngujian rancangan desain model yaitu menentukan alokasi port-port dari komponen-komponen yang akan dihubungkan dan menggambarkan skemanya menggunakan perangkat lunak Fritzing. Ditampilkan pada tabel 1 dan Gambar 3 berikut :

Tabel 1 : Alokasi port komponen

\begin{tabular}{|l|l|l|l|}
\hline No & WeMos D1 Mini & Sensor PIR & Sensor Cahaya \\
\hline 1 & $5 \mathrm{v}$ Vcc & Vcc & Resistor \\
\hline 2 & A0 & - & Output \\
\hline 3 & D0 & Output & - \\
\hline 4 & GND & GND & LDR \\
\hline
\end{tabular}




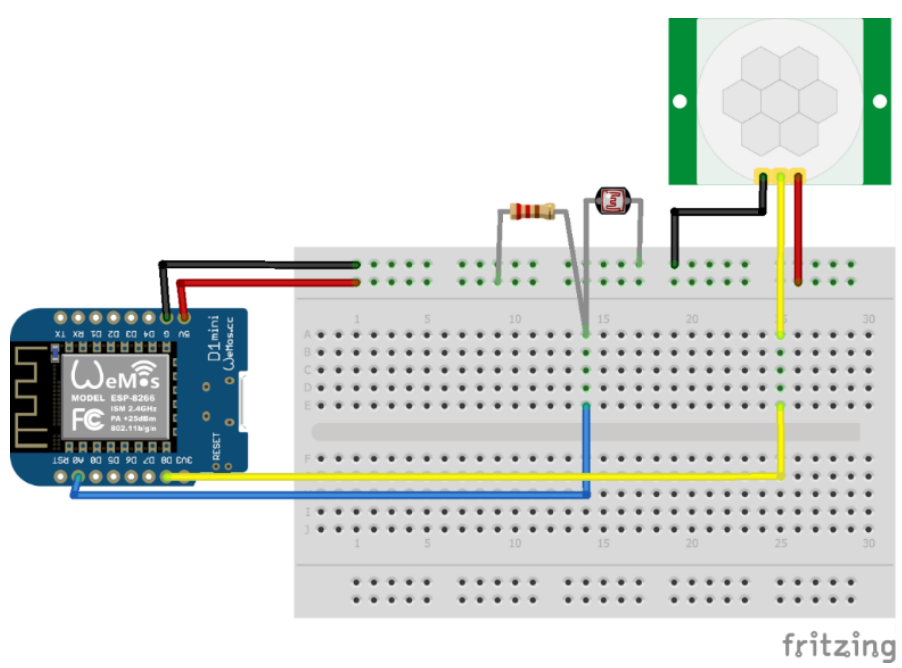

Gambar 3. Skema alokasi port komponen

Perancangan desain model sebagai desain awal menggunakan perangkat lunak SolidWorks 2017 menggunakan skala 1 : 1. Ditampilkan pada Gambar 4 berikut :

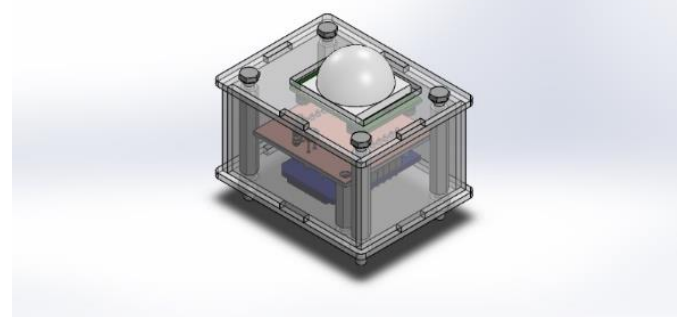

Gambar 4. Desain 3D alat dengan komponen lengkap

Alat yang akan dibuat oleh peneliti merupakan shield atau PCB berukuran 38.5 $\mathrm{mm} \times 37.5 \mathrm{~mm}$ yang berfungsi untuk menghubungkan perangkat sensor PIR dan sensor cahaya dengan WeMos D1 Mini. Setelah selesai mendesain 3D alat dengan komponen lengkap, selanjutnya adalah mendesain casing dari desain alat yang akan dibuat. Selanjutnya adalah pembuatan perangkat keras seperti pada Gambar 5 dan pembuatan aplikasi android menggunakan android studio pada Gambar 6, berikut :

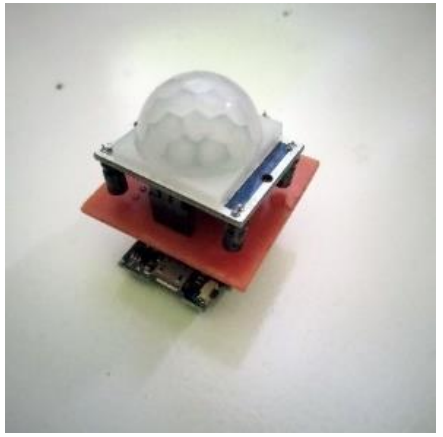

Gambar 5. Hasil pembuatan perangkat keras

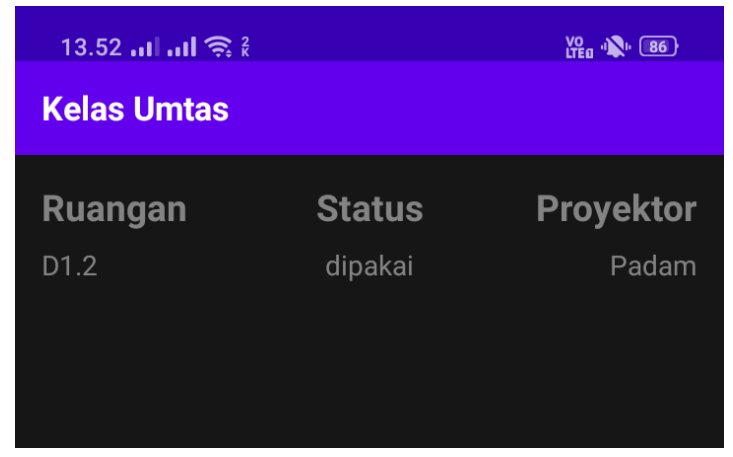

Gambar 6. Antar muka aplikasi android

Pengujian sensor dilakukan pada rentang waktu pertama pada pukul $12.00-13.00 \mathrm{WIB}$, ditampilkan pada tabel 2 dan tabel 3 berikut : 
Tabel 2 : Tabel pengujian hardware ke-1

\begin{tabular}{|c|c|c|c|c|}
\hline No & Pengujian & Test Case & Hasil & $\begin{array}{l}\text { Rasio } \\
\text { Kesalahan }\end{array}$ \\
\hline \multirow{2}{*}{1} & \multirow{2}{*}{$\begin{array}{l}\text { Sensor } \\
\text { Cahaya }\end{array}$} & $\begin{array}{l}\text { Diberi sorotan cahaya } \\
\text { proyektor }\end{array}$ & $\begin{array}{l}\text { Input analog pada WeMos kurang } \\
\text { dari } 2,8 \mathrm{~V}\end{array}$ & $0,87 \%$ \\
\hline & & $\begin{array}{l}\text { Tidak diberi sorotan cahaya } \\
\text { proyektor }\end{array}$ & $\begin{array}{l}\text { Input analog pada WeMos lebih } \\
\text { dari } 2,8 \mathrm{~V}\end{array}$ & $0,01 \%$ \\
\hline \multirow[b]{2}{*}{2} & \multirow[b]{2}{*}{ Sensor PIR } & Diberi sinyal PIR manusia & Pembacaan digital WeMos High & $2,87 \%$ \\
\hline & & $\begin{array}{l}\text { Tidak diberi sinyal PIR } \\
\text { manusia }\end{array}$ & Pembacaan digital WeMos Low & $0,01 \%$ \\
\hline
\end{tabular}

Tabel 3 : Hasil pengujian aplikasi android ke-1

\begin{tabular}{|l|l|l|l|}
\hline No & Form & Harapan & Hasil \\
\hline 1 & $\begin{array}{l}\text { Kolom status } \\
\text { ruangan }\end{array}$ & $\begin{array}{l}\text { Bertulisan "Dipakai" ketika sensor PIR atau cahaya mendeteksi } \\
\text { keberadaan manusia atau proyektor, dan bertulisan “kosong” ketika } \\
\text { sebaliknya }\end{array}$ & $\begin{array}{l}\text { Sesuai } \\
\text { harapan }\end{array}$ \\
\hline 2 & $\begin{array}{l}\text { Kolom kondisi } \\
\text { proyektor }\end{array}$ & $\begin{array}{l}\text { Bertulisan "Nyala" ketika sensor cahaya saja mendeteksi cahaya } \\
\text { proyektor, dan bertulisan "padam" ketika sebaliknya }\end{array}$ & $\begin{array}{l}\text { Sesuai } \\
\text { harapan }\end{array}$ \\
\hline
\end{tabular}

Pengujian kedua pada rentang pukul $11.45-12.45 \mathrm{WIB}$, ditampilkan pada tabel 4 dan tabel 5 berikut:

Tabel IV4: Hasil pengujian hardware ke-2

\begin{tabular}{|l|l|l|l|l|}
\hline No & Pengujian & Test Case & Hasil & $\begin{array}{l}\text { Rasio } \\
\text { Kesalahan }\end{array}$ \\
\hline \multirow{2}{*}{1} & \multirow{2}{*}{$\begin{array}{l}\text { Sensor } \\
\text { Cahaya }\end{array}$} & $\begin{array}{l}\text { Diberi sorotan cahaya } \\
\text { proyektor }\end{array}$ & $\begin{array}{l}\text { Input analog pada WeMos kurang } \\
\text { dari 2,8V }\end{array}$ & $0,66 \%$ \\
\cline { 3 - 5 } & $\begin{array}{l}\text { Tidak diberi sorotan cahaya } \\
\text { proyektor }\end{array}$ & $\begin{array}{l}\text { Input analog pada WeMos lebih } \\
\text { dari 2,8V }\end{array}$ & $0,01 \%$ \\
\hline \multirow{2}{*}{2} & \multirow{2}{*}{ Sensor PIR } & $\begin{array}{l}\text { Diberi sinyal PIR manusia } \\
\text { Tidak diberi sinyal PIR } \\
\text { manusia }\end{array}$ & Pembacaan digital WeMos High & $3,53 \%$ \\
\hline
\end{tabular}

Tabel 5: Hasil pengujian aplikasi android ke-2

\begin{tabular}{|c|l|l|l|}
\hline No & Form & Harapan & Hasil \\
\hline 1 & $\begin{array}{l}\text { Kolom status } \\
\text { ruangan }\end{array}$ & $\begin{array}{l}\text { Bertulisan "Dipakai" ketika sensor PIR atau cahaya mendeteksi } \\
\text { keberadaan manusia atau proyektor, dan bertulisan "kosong” ketika } \\
\text { sebaliknya }\end{array}$ & $\begin{array}{l}\text { Sesuai } \\
\text { harapan }\end{array}$ \\
\hline 2 & $\begin{array}{l}\text { Kolom kondisi } \\
\text { proyektor }\end{array}$ & $\begin{array}{l}\text { Bertulisan "Nyala" ketika sensor cahaya saja mendeteksi cahaya } \\
\text { proyektor, dan bertulisan "padam" ketika sebaliknya }\end{array}$ & $\begin{array}{l}\text { Sesuai } \\
\text { harapan }\end{array}$ \\
\hline
\end{tabular}

Pengujian ketiga pada rentang pukul 10.00 - 11.00 WIB, ditampilkan pada tabel 6 dan tabel 7 berikut:

Tabel 6 : Hasil pengujian hardware ke-3

\begin{tabular}{|l|l|l|l|l|}
\hline No & Pengujian & Test Case & Hasil & $\begin{array}{l}\text { Rasio } \\
\text { Kesalahan }\end{array}$ \\
\hline \multirow{2}{*}{$\begin{array}{l}\text { Sensor } \\
\text { Cahaya }\end{array}$} & $\begin{array}{l}\text { Diberi sorotan cahaya } \\
\text { proyektor }\end{array}$ & $\begin{array}{l}\text { Input analog pada WeMos kurang } \\
\text { dari 2,8V }\end{array}$ & $1,87 \%$ \\
\cline { 3 - 5 } & $\begin{array}{l}\text { Tidak diberi sorotan cahaya } \\
\text { proyektor }\end{array}$ & $\begin{array}{l}\text { Input analog pada WeMos lebih } \\
\text { dari 2,8V }\end{array}$ & $0,01 \%$ \\
\hline \multirow{2}{*}{\begin{tabular}{l} 
Sensor PIR \\
\cline { 2 - 4 }
\end{tabular}} & $\begin{array}{l}\text { Diberi sinyal PIR manusia } \\
\text { Tidak diberi sinyal PIR }\end{array}$ & Pembacaan digital WeMos High & $1,35 \%$ \\
\hline
\end{tabular}


Tabel 7 : Hasil pengujian aplikasi android ke-3

\begin{tabular}{|l|l|l|l|}
\hline No & Form & Harapan & Hasil \\
\hline 1 & $\begin{array}{l}\text { Kolom status } \\
\text { ruangan }\end{array}$ & $\begin{array}{l}\text { Bertulisan "Dipakai” ketika sensor PIR atau cahaya mendeteksi } \\
\text { keberadaan manusia atau proyektor, dan bertulisan "kosong” ketika } \\
\text { sebaliknya }\end{array}$ & $\begin{array}{l}\text { Sesuai } \\
\text { harapan }\end{array}$ \\
\hline 2 & $\begin{array}{l}\text { Kolom kondisi } \\
\text { proyektor }\end{array}$ & $\begin{array}{l}\text { Bertulisan "Nyala" ketika sensor cahaya saja mendeteksi cahaya } \\
\text { proyektor, dan bertulisan "padam" ketika sebaliknya }\end{array}$ & $\begin{array}{l}\text { Sesuai } \\
\text { harapan }\end{array}$ \\
\hline
\end{tabular}

Dari beberapa pengujian terlihat bahwa pengujian alat sebanyak 3 kali, jumlah item dalam instrumen $\mathrm{k}=4$, yaitu sensor cahaya yang diberi cahaya proyektor, sensor cahaya yang tidak diberi cahaya proyektor, sensor PIR yang diberi sinyal PIR, dan sensor PIR yang tidak diberi sinyal PIR. Rasio kesalahan rata-rata sensor cahaya ketika proyektor dinyalakan adalah $1,13 \%$ atau 1 kesalahan dari 100 periode pengujian, sedangkan ketika dimatikan adalah $0,01 \%$ atau 0 kesalahan dari 100 periode pengujian. Untuk sensor PIR ketika diberi sinyal PIR manusia rasio kesalahan rata-ratanya adalah 2,58\% atau 3 kesalahan dari 100 periode pengujian, sedangkan ketika tidak diberi sinyal PIR manusia rasionya adalah $0,01 \%$ atau 0 dari 100 periode pengujian. Sehingga jumlah subjek adalah jumlah periode dalam penerimaan data dari sensor yaitu $\mathrm{p}=100$. Maka diketahui, bahwa nilai $k=4, S t^{2}=0,1936, M=3,92$ dan nilai reliabilitas instrumen yang didapat adalah sebagai berikut :

$$
\begin{aligned}
r_{i} & =\frac{4}{4-1}\left\{1-\frac{3,92(4-3,92)}{4 \times 0,1936}\right\} \\
& =0,793388
\end{aligned}
$$

Hasil perhitungan uji reliabilitas instrumen dengan rumus kuder richardson[13], didapatkan hasil reliabilitas instrumen sebesar 0,793388 (tinggi).

\section{KESIMPULAN}

Setelah melakukan proses perancangan, evaluasi design, implementasi, dan pengujian, sistem monitoring ruang kuliah dengan aplikasi android berbasis chip ESP8266, maka peneliti dapat menarik kesimpulan sebagai berikut :

1. Sistem monitoring ruang kuliah dengan aplikasi android berbasis chip ESP8266 dengan menggunakan sensor cahaya dan sensor PIR sebagai masukan data. Unjuk kerja sistem monitoring ruangan mendapatkan hasil sesuai dengan harapan, dimana keseluruhan instrumen dapat bekerja dengan baik dan reliabel dalam proses pengujian reliabilitas.

2. Sensor PIR dapat mendeteksi PIR hingga jarak maksimal 4 meter.

3. Sensor PIR akan lebih efektif dengan pengaturan time delay sekitar 3 menit, namun konsekuensinya informasi ruangan yang baru kosong akan kurang up to date selama 3 menit.

\section{DAFTAR PUSTAKA}

[1] Abdullah, Andi (2018). Monitoring Penyimpanan Kebutuhan Pokok Menggunakan Thingspeak Berbasis IoT. Information Technology Engineering Journals, 03(01).

[2] Agung Prijambodo, Dimas. 2017. Purwarupa Sistem Menyalakan dan Mematikan Lampu Ruangan Berbasis Android Dengan WeMos D1 Mini. Skripsi, tidak diterbitkan. Surakarta: Fakultas Teknik Universitas Muhammadiyah Surakarta. 
[3] Akhmad Najih, Reza., Hannats Hanafi Ichsan, Mochammad., \& Kurniawan, Wijaya. (2018). Monitoring Kelembaban, Suhu, Intensitas Cahaya Pada Tanaman Anggrek Menggunakan ESP8266 dan Arduino. Jurnal Pengembangan Teknologi Informasi dan Ilmu Komputer, 02(11), $4607-4612$.

[4] Astianto Gae, Riovanus., Triyanto Dedi., \& Suhardi. (2019). Rancang Bangun Sistem Pemantauan dan Notifikasi Otomatis Pada Keamanan Rumah Menggunakan Teknologi Wireless Sensor Network Berbasis Website. Jurnal Komputer dan Aplikasi, 07(03), 23 - 33.

[5] Espressif Systems. 2020. ESP8266EX Datasheet. Shanghai. Espressif Systems.

[6] Fauzan Jaya, Ahmad., Ary Murti, Muhammad., \& Mayasari, Ratna. (2018). Monitoring dan Kendali Perangkat Pada Ruang Kelas Berbasis Internet of Things (IoT). E-Proceeding of Engineering, 05(01), 22 - 31.

[7] Gifson, Albert \& Slamet (2009). Pemantau Ruang Jarak Jauh Dengan Sensor Passive Infrared Berbasis Mikrokontroler AT89S52. Jurnal Telkomnika, 7, 201-206.

[8] Gunawan, Dedi. (2018). Sistem Monitoring Distribusi Air Menggunakan Android Blynk. Information Technology Engineering Journals, Vol 3 - No 01 .

[9] Waloyo Tricahyono, Rizki., \& Kholis, Nur. (2018). Sistem Monitoring Intensitas Cahaya dan Daya Pada Dual Axis Solar Tracking System Berbasis IoT. Jurnal Teknik Elektro, 07(04), 233 - 238.

[10] Kusumaningrum, Anggriani., Puiastutu, Asih., \& Zeny, Muhammad. (2017). Pemanfaatan Internet of Things Pada Kendali Lampu. Jurnal Teknik Informatika 06(01), 53 - 59.

[11] Setiadi, David., \& Nurdin Abdul Muhaemin, Muhammad (2018). Penerapan Internet of Things (IoT) Pada Sistem Monitoring Irigasi (Smart Irigasi). Jurnal Infotronik, 03(02), 93-102.

[12] Samsugi, S., Ardiansyah., \& Kastutara, Dyan (2018). Arduino dan Modul WiFi ESP8266 Sebagai Media Kendali Jarak Jauh Dengan Antar Muka Berbasis Android. Jurnal Teknoinfo, 12, 23-37.

[13] Sugiyono. 2015. Metode Penelitian Pendidikan: Pendekatan Kuantitatif, Kualitatif, dan R\&D. Bandung: Alfabeta. 